\title{
Exploring eating and exercise-related indicators during COVID-19 quarantine in Portugal: concerns and routine changes in women with different BMI
}

\author{
Maria Coimbra $^{1}\left[\right.$ Carolina Paixão $^{1}\left[\right.$ Cláudia Ferreira $^{1}[$
}

Received: 12 November 2020 / Accepted: 1 March 2021 / Published online: 22 March 2021

(c) The Author(s), under exclusive licence to Springer Nature Switzerland AG 2021

\begin{abstract}
Purpose The present study aimed to understand how quarantine associated with COVID-19 was experienced by women from different BMI groups (underweight, normal weight, pre-obesity, and obesity), by exploring the changes introduced in eating and exercise routines and the differences between BMI groups regarding shape concern, weight concern, and binge eating behaviours reported during this time.

Methods This study comprised 580 women aged between 18 and 65 years old, who completed self-report measures, during the mandatory confinement in Portugal due to COVID-19. The total sample was divided into four groups, according to their BMI.

Results Results revealed that overall, there were no significant differences between the groups regarding the eating and exercise routine changes introduced during quarantine. However, significant differences between the four groups were found in the reported body and eating-related difficulties (shape concern, weight concern, and binge eating behaviours), with the pre-obesity and obesity groups presenting significant higher levels.

Conclusions Our study suggests that, even though the changes introduced to the eating and exercise routine are independent of BMI, the pre-obesity and obesity group represent a major vulnerability group for the development of eating disorders. We hope this study allows professionals to understand the need to develop different guidelines and strategies for the pre-obesity and obesity female population during the deconfinement period.
\end{abstract}

Level of evidence Level V-Descriptive study.

Keywords COVID-19 Eating routine changes $\cdot$ Exercise routine changes $\cdot$ Shape and weight concern $\cdot$ Binge eating $\cdot$ BMI

\section{Introduction}

The coronavirus SARS-CoV-2, identified in China at the end of 2019, and the disease it causes (COVID-19), has triggered a large outbreak that became a pandemic and a great public health emergency [1]. Due to the absence of a vaccine and an approved treatment protocol, the World Health Organization [1] announced that to control the spread and infection

Maria Coimbra

maria.rcoimbra@gmail.com

1 CINEICC-Center for Research in Neuropsychology and Cognitive Behavioral Intervention, Faculdade de Psicologia e Ciências da Educação, Universidade de Coimbra, Rua do Colégio Novo, Apartado 6153, 3001-802 Coimbra, Portugal rate of this global pandemic, confinement and other social distancing measures were required.

On March 19, 2020, the Portuguese government installed a state of emergency in Portugal. The state of emergency is an exceptional regime, in which certain rights are suspended, with the sole purpose of adopting the necessary measures for the protection of public health, in this case, in the context of the COVID-19 pandemic. Thus, a set of measures were implemented to contain the disease, namely: compulsive confinement at home or in a health establishment; prohibition of unjustified travel; closure or limitation of commercial activities; mandatory work from home, except for essential workers; cross-border controls; limitation or prohibition of holding meetings or demonstrations that, due to the number involved, enhance the transmission of the new Coronavirus, including religious events and celebrations. This state 
of emergency ended, in Portugal, on May 3, 2020, and all imposed measures were lifted or adapted [2].

Besides being a public physical health emergency, the COVID-19 outbreak and subsequent prevention and control strategies, also seem to have a great psychological and social impact [3,37]. Recent studies have reported that the coronavirus pandemic, its exponential spike in disease and death, and the subsequent compulsory global lockdown (from school and university closures, travel restrictions, or full lockdowns) has brought a parallel emotional pandemic of fear, stress, anxiety, and depression [4]. Several authors have pointed out that beyond the potential benefits to control the outbreak, the mandatory confinement and other social distancing measures will have psychological costs [5].

Regarding the field of eating psychopathology, this stressful situation is associated with substantial changes in daily routines, which for many people may lead to or intensify body and eating-related difficulties. The daily routine changes due to COVID-19 quarantine (e.g., eating and foodrelated practices, the closing of gyms, movement restriction, and confinement) may contribute to weight and body shaperelated preoccupation (e.g., fear of weight gain) and promote disordered eating behaviours (ranging from severe caloric restriction to overeating; [6]). Previous studies have shown that food insecurity, defined by the perception of limited access to food by contextual or financial hardship, is associated with increased binge eating behaviours [7]. On the other hand, being at home for extended periods and the continuous exposure to food during confinement can, also, be a trigger to binge eating behaviours [8]. Moreover, emotional eating and binge eating may occur as a maladaptive emotional strategy to suppress or soothe negative emotional experiences (e.g., anxiety, anger, or boredom), frequently experienced in distressing and challenging contexts $[9,10]$.

Disordered eating behaviours (DEBs) are described as serious maladaptive eating behaviours that comprise a high clinical burden, whether or not they warrant a diagnosis of a specific eating disorder [11]. Among the spectrum of DEBs (such as dietary restrictions, fasting, binging, or other unhealthy behaviours to control weight and/or body shape), binge eating episodes have consistently shown to be the most prevalent [12-18].

Binge eating is characterized by the consumption of an unusually large amount of food in a discrete-time period, with a sense of lack of control over one's eating [19], accompanied by severe discomfort or distress [20]. There is increased recognition that binge eating is a serious public health concern, even when in its sub-clinical forms [16]. In addition to its high prevalence, there is empirical evidence that suggests that binge eating episodes tend to become recurrent and progressively more severe [21], which may contribute to the development of a clinical form of eating disorder and carry harmful physical and mental health consequences, such as obesity [22], as well as poor psychological adjustment $[14,15]$. Additionally, weight and shape concern have been found to be related to certain eatingrelated difficulties [23, 24], often appearing as a risk factor or/and a symptom for the development of eating disorders $[25,26]$.

Body Mass Index (BMI) has been described as having a crucial role in the development of disordered eating attitudes and behaviours (e.g. restrictive practices; binge eating behaviours; the use of compensatory behaviours [27, 29]). More specifically, the relationship between the development of eating-related difficulties and a higher BMI (preobesity and obesity group samples) has been thoroughly explored, with the studies emphasizing the importance and significance of this, especially in young female samples [23, 30-32]. With this information, it is important to explore the role that BMI takes on during a strenuous time, such as quarantine.

Considering the need to further understand BMI's role in eating-related difficulties, this study aimed to explore how women from different BMI groups (underweight, normal weight, pre-obesity, and obesity; [33]) experienced quarantine (i.e., isolation, confinement, the closing of gyms, continuous exposure to food, etc.). Particularly: (i) exploring the changes introduced in eating and exercise routines and (ii) understand how shape concern, weight concern, and binge eating behaviours manifested during this time.

We hypothesized that (i) eating and exercise routinerelated changes introduced by women during quarantine varied according to the belonging BMI group and that (ii) women from the obesity group would experience in this period more shape concern, weight concern, and binge eating, in comparison to the other BMI groups.

\section{Methods}

\section{Participants}

The study's initial sample was composed of 705 participants from the Portuguese general population, with ages ranging from 17 to 74 years old. Exclusion criteria were applied, excluding (a) male participants and (b) participants younger than 18 years old or older than 65 years old; which corresponded to $17.73 \%$ of the initial sample. The final sample included 580 female participants from the Portuguese general population.

\section{Procedures}

All procedures regarding data collection respected the ethical and deontological requirements inherent to scientific research in psychology. This cross-sectional study was 
conducted during the mandatory confinement in Portugal due to COVID-19, between April 17th and May 3rd, starting 30 days after the implementation of this mandatory confinement that lasted 45 days.

Data collection was conducted through an online survey and participants were invited via different social networks. The participants who chose to participate in this study were immediately informed of its' aims and procedures as well as the confidential and voluntary character of their participation. Before answering the questionnaire, all participants had to sign an informed consent document. In this study, there were no missing data since all questions were of mandatory answer.

\section{Measures}

Demographic Data. Participants reported their demographic data information (sex, age, years of education, area of residence, and civil status).

Body Mass Index (BMI). The Body Mass Index was calculated by dividing self-reported current weight by the height squared $\left(\mathrm{kg} / \mathrm{m}^{2}\right)$.

In all the self-reported measures, participants were asked to report their experiences considering only the previous 30 days (corresponding to the 30 days of quarantine).

Changes in the eating and exercise routine. Participants were asked: "Please check all the changes introduced in your eating routine during quarantine/Please check all the changes introduced in your exercise routine during quarantine. For each of the 14 items ( 7 concerning eating routine changes and 7 concerning exercise routine changes; presented in more detail in Table 1), participants are asked to report whether each statement applies to them or not, through "yes" or "no" answers. The full item list can be found in Appendix 1.

Weight and Shape concern. To access the participant's concern about weight and body shape during the last 30 days, 6 items from the Eating Disorder Questionnaire (EDE-Q [34, 35]) were chosen. Three items access Shape Concern and three items access Weight Concern (items correspond to questions 29-36 from the original scale). Participants answered each statement using a 6-point Likert-scale (ranging from $0=$ "None" and $6=$ "Extremely"). In the current study, Weight Concern scale had an $\alpha$ of 0.74 and Shape Concern scale an $\alpha$ of 0.94 .

Binge Eating Scale (BES; [10, 36]). BES is a self-report measure that assesses the behavioural, cognitive, and emotional features of binge eating. BES includes 16 items, each with 3 or 4 statement options, coded from zero to two or three, with higher values indicating higher severity of binge eating. This measure presents good psychometric properties, with a Cronbach's alpha of 0.85 in the original study, a
Cronbach's alpha of 0.88 in the Portuguese version, and of 0.90 in the current one.

\section{Data analyses}

Data analyses were performed using the IBM SPSS Statistics 22.0 software (SPSS IBM; Chicago, IL).

Descriptive statistics regarding the eating routine changes introduced during quarantine (\%) were explored, and group differences were examined through chi-squared tests.

Differences between the BMI groups regarding the study's variables (shape concern, weight concern, and BES) were explored through a One-way ANOVA, using the Tukey HSD test for post hoc comparisons.

\section{Results}

\section{Preliminary data}

Preliminary analyses indicated that there was no severe violation of normal distribution. Skewness values ranged from 0.29 (Shape Concern) to 1.48 (BES) and Kurtosis values ranged from 1.11 (Shape Concern) to 2.43 (BES) $(|\mathrm{Sk}|<3$ and $|\mathrm{Ku}|<8-10$; [40]).

\section{Descriptive analyses}

The study's sample $(\mathrm{N}=580)$ had an age mean of 26.91 $(S D=9.43)$ and a mean of $14.76(S D=2.40)$ years of education. Most of the participants (56.2\%) resided in an urban area, $24.1 \%$ in a semi-urban and $19.7 \%$ in a rural area. Additionally, $80.7 \%$ of women reported being single, $15.9 \%$ married, $2.9 \%$ divorced, and $0.5 \%$ widowed. The BMI mean for the total sample was $22.68(S D=3.94)$. Forty-nine $(8.45 \%)$ women presented as underweight, $407(70.17 \%)$ as normal weight, 96 (16.55\%) pre-obesity, and 28 (4.83\%) obesity. The four BMI groups presented significant differences in age $\left(F_{(3)}=14.23 ; E t a=0.07 p=0.000\right)$, marital status $\left(X_{(9)}^{2}=0.16 ; p=0.000\right)$ and area of residence $\left(X^{2}{ }_{(6)}=0.10\right.$; $p=0.050)$. No significant differences were found regarding years of education $\left(F_{(3)}=0.38 ; E t a=0.00 ; p=0.769\right)$.

\section{Eating and exercise routine changes introduced during COVID-19 quarantine}

Regarding the eating routine changes introduced during quarantine (Fig. 1), overall results indicated that the most frequent changes reported were "I feel more need to ingest comfort foods" (ranging from $46.9 \%$ to $71.44 \%$ ) and "I feel more need to consume food in between meals" (ranging from $41.7 \%$ to $51.1 \%$ ). Chi-squared tests were performed, and the only eating routine change that presented 


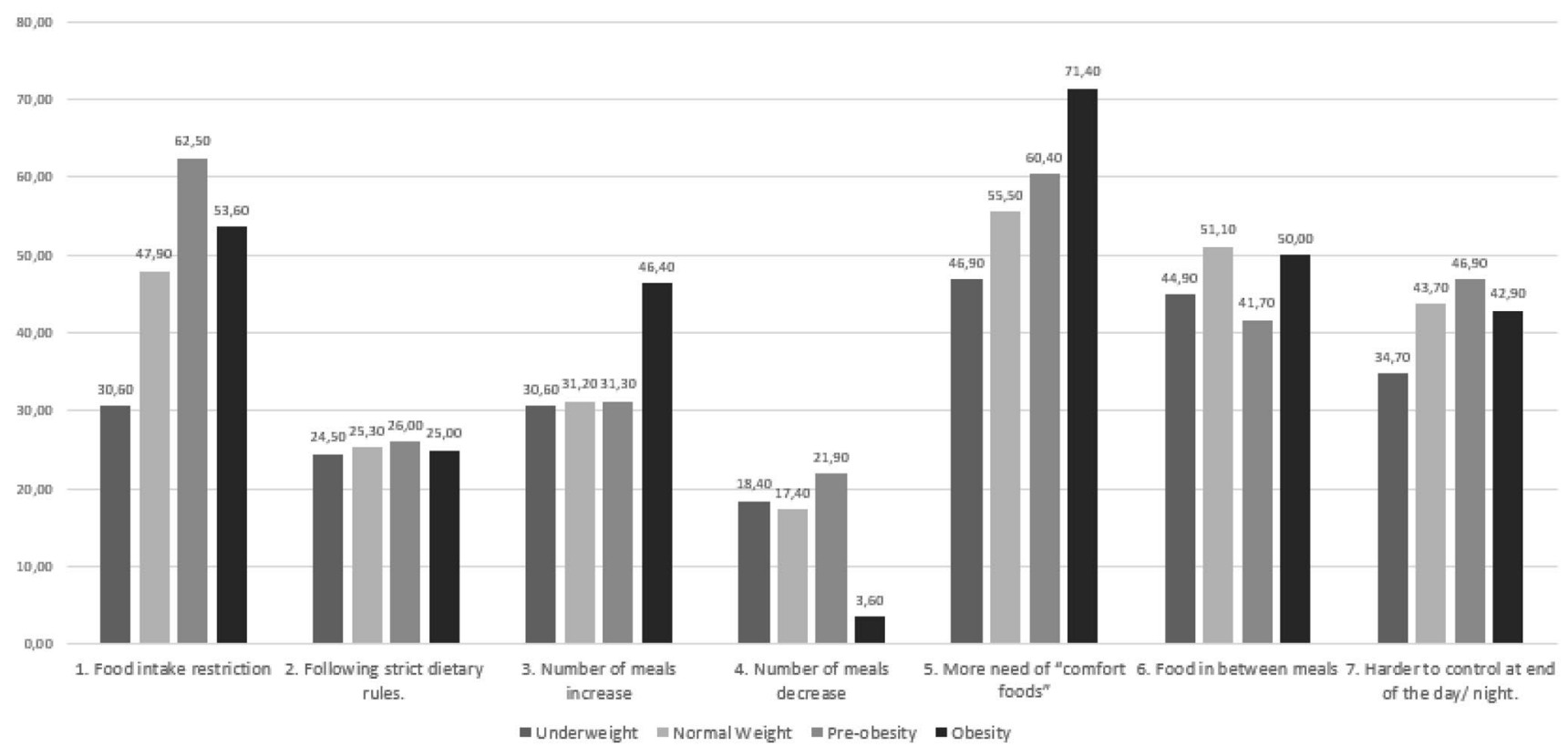

Fig. 1 Reported eating routine changes introduced during COVID-19 quarantine (percentage of affirmative answers) by BMI groups

significant differences between the BMI groups were "I tried to limit my food intake to control my weight or body shape" $\left(X^{2}{ }_{(3)}=13.46 ; p=0.004\right.$; from $30.6 \%$ in the underweight group to $62.5 \%$ in the obesity group).

Regarding the exercise routine changes (Fig. 2), most participants (from all BMI groups) reported the change "I tried to initiate an exercise plan to control my weight or body shape" (from 53.1\% in the underweight group and 64.3\% in the obesity group). Two exercise routine changes presented significant differences between the BMI groups: "I increased the number of times per week that I practice exercise" $\left(X_{(3)}^{2}=8.32 ; p=0.040\right.$; with the normal group presenting the highest values and the obesity group the lowest) and "I completely interrupted my exercise practice" $\left(X_{(3)}^{2}=8.77\right.$;

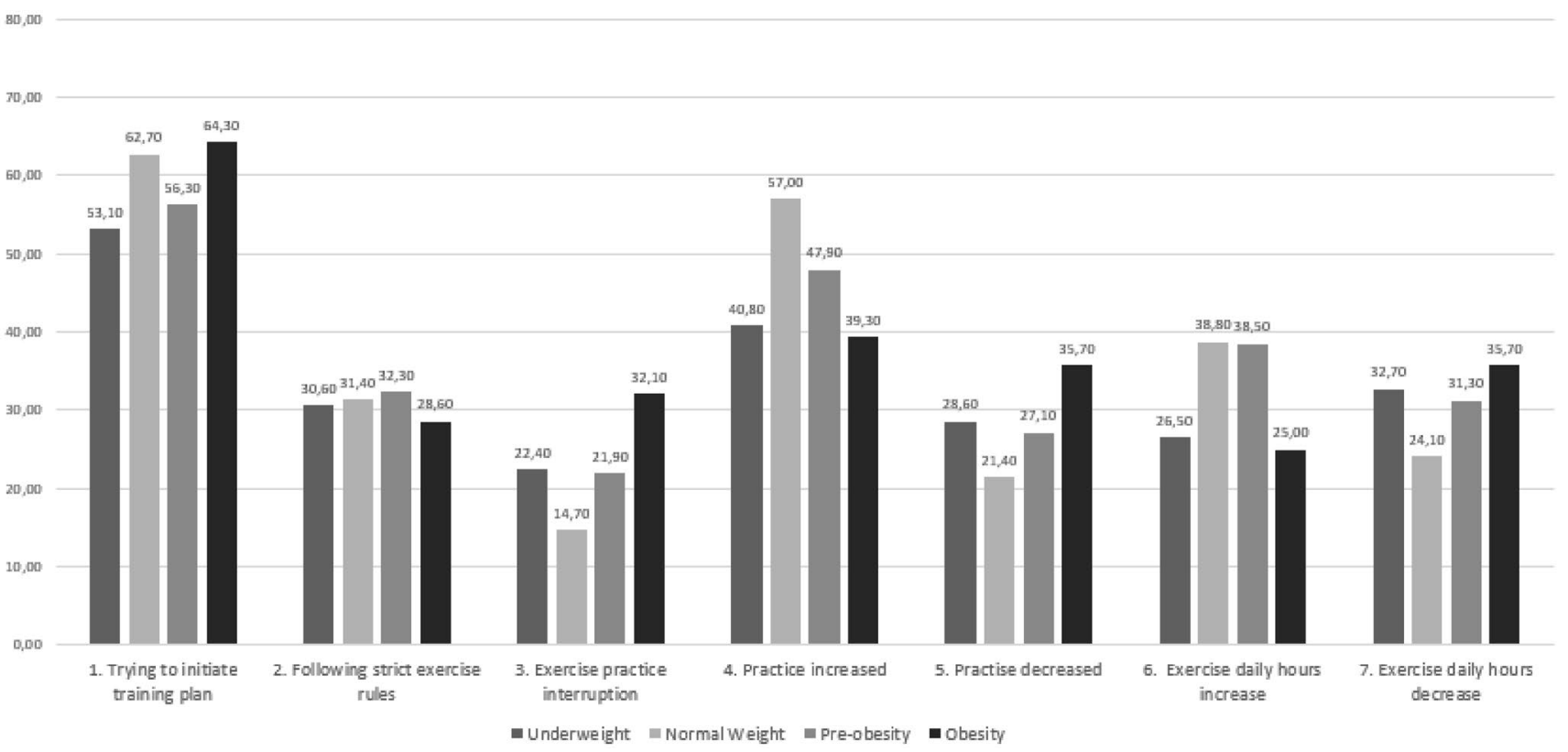

Fig. 2 Reported exercise routine changes introduced during COVID-19 quarantine (percentage of affirmative answers) by BMI groups 
$p=0.033$; with the obesity group presenting higher values and the normal group the lowest).

\section{BMI group differences between body and eating-related difficulties and binge eating symptomatology during COVID-19 quarantine}

The BMI groups presented significant differences between them regarding shape concern, weight concern, and binge eating symptomatology (BES), during COVID-19 quarantine. The results revealed that women from the obesity group and the pre-obesity group presented significant higher levels of the mentioned indicators when compared to the normal and underweight group (Table 1).

\section{Discussion}

Social isolation, separation from loved ones, loss of freedom, and boredom associated with quarantine times can have negative psychological effects [3, 37]. The COVID-19 pandemic, and its associated mandatory quarantine, unequivocally lead to daily routine changes, which might create a context that enhances certain body and eating-related difficulties. BMI is an important factor to consider when exploring eating-related difficulties, considering its crucial role in the development of disordered eating attitudes and behaviours [27, 28].

This study was conducted in a sample of 580 women of the general population, with the data being collected during the confinement period, starting 30 days after the implementation of the mandatory confinement in Portugal duo to COVID-19. To deeply understand the main changes regarding eating and exercise practice in women belonging to different BMI categories, the sample was divided into four groups, having into account the BMI groups defined by WHO [33].

Therefore, to understand how women from different BMI groups reported eating-related difficulties experienced during COVID-19 quarantine, we intended to explore: (i) the changes introduced in the eating and exercise routines and (ii) how shape concern, weight concern, and binge eating behaviours manifested during this time.

Unlike what was initially predicted, the results indicated that there were no significant differences regarding the eating-related routine changes between the four BMI groups, which may indicate that changes introduced by women in their eating routine during quarantine were independent of their BMI. An exception was verified in the intention "to limit my food intake to control my weight or body shape", mostly reported by the pre-obesity (62.5\%) and least reported by the underweight group $(30.6 \%)$. This result is supported by literature, suggesting that food restriction is a strategy mainly adopted by women with a higher BMI.

Regarding the exercise routine changes, there were overall no significant differences found between the BMI groups. However, the changes "I completely interrupted my exercise practice" and "I increased the number of times per week that I practice exercise" did present significant differences between the groups, with the normal weight group reporting the first mentioned change the least (14.7\%) and the latter the most (57.0\%). This may indicate that the normal weight group is the group that most reports investment in exercise during quarantine, using it as the main strategy to control weight and body shape.

These results did not confirm our initial hypothesis, since we expected to find significant differences between the groups regarding the changes introduced to the eating and exercise routines. However, these results show that quarantine, and its associated factors (such as confinement, the closing of gyms, and continuous food exposure), had a significant impact on women's eating and exercise routines, with the overall introduction of major changes in all groups.

Concerning the differences between BMI groups in the body and eating-related difficulties, women with higher values of BMI (pre-obesity and obesity groups) reported higher levels of weight concern, shape concern, and binge eating symptomatology. These results are in line with prior studies [23, 30-32] and confirm our initial hypothesis but seem to suggest that women from the pre-obesity group report similar difficulties to the obesity group. Evidently, it is expected that women with higher BMI present higher levels of the mentioned body and eating-related indicators even in normal
Table 1 Means (M) and standard deviations (SD) and ANOVA results for comparison between BMI groups

\begin{tabular}{|c|c|c|c|c|c|c|c|c|c|c|c|}
\hline & \multicolumn{2}{|c|}{$\begin{array}{l}\text { Under- } \\
\text { weight } \\
(n=49)\end{array}$} & \multicolumn{2}{|c|}{$\begin{array}{l}\text { Normal } \\
\text { weight } \\
(n=407)\end{array}$} & \multicolumn{2}{|c|}{$\begin{array}{l}\text { Pre-obesity } \\
(n=96)\end{array}$} & \multicolumn{2}{|c|}{$\begin{array}{l}\text { Obesity } \\
(n=28)\end{array}$} & \multirow[t]{2}{*}{$F ; d f$} & \multirow[t]{2}{*}{$p$} & \multirow[t]{2}{*}{ Post hoc } \\
\hline & $M$ & $S D$ & $M$ & $S D$ & $M$ & $S D$ & $M$ & $S D$ & & & \\
\hline Shape concern & 2.34 & 1.75 & 2.38 & 1.74 & 3.48 & 1.90 & 4.01 & 1.51 & $22.31 ; 3$ & .000 & $\mathrm{UW} ; \mathrm{NW}<\mathrm{PO} ; \mathrm{O}$ \\
\hline Weight concern & 1.90 & 1.59 & 1.86 & 1.50 & 2.97 & 1.64 & 3.58 & 1.51 & $16.51 ; 3$ & .000 & $\mathrm{UW}$; NW < PO; O \\
\hline BES & 6.89 & 7.34 & 7.69 & 6.88 & 12.15 & 9.23 & 15.11 & 10.39 & $16.77 ; 3$ & .000 & $\mathrm{UW} ; \mathrm{NW}<\mathrm{PO} ; \mathrm{O}$ \\
\hline
\end{tabular}

Note $B E S$ binge eating scale 
circumstances (non-confinement). It is possible, however, that the confinement period has exacerbated these concerns and behaviours.

Some limitations need to be considered. The cross-sectional nature of the study does not allow for causal conclusions to be draught. Thus, future research should use longitudinal designs to better understand these relationships. The sample used also represents a limitation since the BMI groups had significant sociodemographic differences between them. Moreover, research demonstrates that, even though women are consistently studied regarding body and eating-related difficulties, these may also have a deleterious effect in men [38, 39], so the study should be replicated with both genders. Finally, the questions of eating and exercise routine changes were formulated by the authors, there is a possibility that other changes occurred during quarantine but were not reported.

The present study offers new empirical data, by suggesting that COVID-19 quarantine had an impact on women's eating and exercise routines, showing that these changes are common to all BMI groups. Our results also suggest that the BMI groups can be divided into two focus/main groups (underweight and normal weight group vs. pre-obesity and obesity group), regarding the eating-related difficulties found during this strenuous time.

Concluding, it is important that during the crucial deconfinement period, the guidelines and intervention or support programs provided have into account the differences reported by the BMI groups regarding eating-related difficulties. Mostly, we hope this study allows professionals to understand the need to develop different guidelines and strategies for the pre-obesity and obesity female population. These women presented higher levels of shape and weight concern, as well as, higher severity of binge eating, which means they are a major vulnerability group for the development of disordered eating behaviours. Although the adopted changes introduced to the eating and exercise routines, used to deal with the adjustments imposed by mandatory isolation (such as confinement; closing of gyms; continuous exposure to food), seem to be independent of BMI, it is possible that its medium/long-term consequences may be different between women from different BMI groups, specifically between underweight/normal weight women and women from the pre-obesity/obesity groups.

In the future, we hope to be able to replicate this study in a normal (non-isolation) period, to compare the results in different conditions, confirming the possible eating-related risks associated with quarantine.

\section{What is already known on this subject?}

COVID-19 and associated preventive measures have a physical and psychological impact, including in eating-related difficulties. BMI has a crucial role in the development of disordered eating behaviours.

\section{What does this study add?}

During COVID-19 isolation, women introduced changes to their eating and exercise routines, independently from their BMI. However, the pre-obesity and obesity group represent a major vulnerability group for the development of eating disorders. 


\section{Appendix}

Appendix 1 Items from reported eating and exercise routine changes during COVID-19 quarantinein Portugal

\section{Dietary changes}

1. I tried to limit my food intake to control my weight or body shape

2. I tried to follow strict rules concerning my diet

3. I increased the number of meals I have in a day

4. I decreased the number of meals I have in a day

5. I feel more need to ingest "comfort foods"

6. I feel more need to consume food in between meals

7. I feel that it is harder to control what I eat towards the end of the day or even during thenight

\section{Exercise changes}

1. I tried to initiate a training plan to control my weight or body shape

2. I tried to follow strict exercise-related rules to control my weight or body shape

3. I completely interrupted my exercise practice

4. I increased the number of times per week that I practice exercise

5. I decreased the number of times per week that I practice exercise

6. I increased my daily hours of exercise

7. I decreased my daily hours of exercise

Availability of data and material Data are available upon request from the authors.

\section{Declarations}

Conflict of interest The authors declare no conflict of interest and that all authors approved the final manuscript.

Ethical statement All ethical requirements were approved by the Ethics Committee of the Faculty of Psychology and Educational Sciences of the University of Coimbra. Participants signed and delivered their written informed consent.

Informed consent All participants provided their informed consent before entering the study.

\section{References}

1. World Health Organization (2020) Statement on the second meeting of the International Health Regulations (2005) Emergency Committee regarding the outbreak of novel coronavirus (2019nCoV). https://www.who.int/news-room/detail/30-01-2020-state ment-on-the-second-meeting-of-the-international-health-regul ations-(2005)-emergency-committee-regarding-the-outbreak-ofnovel-coronavirus-(2019-ncov)

2. Decreto do Presidente da República n. ${ }^{\circ}$ 14-A/2020, March 18, 2020). Accessed on October 30. Available in https://data.dre.pt/ eli/decpresrep/14-A/2020/03/18/p/dre
3. Wang C, Pan R, Wan X, Tan Y, Xu L, McIntyre RS, Choo FN, Tran B, Ho R, Sharma VK, Ho C (2020) A longitudinal study on the mental health of general population during the COVID-19 epidemic in China. Brain Behav Immun 87:40-48. https://doi.org/ 10.1016/j.bbi.2020.04.028

4. Yao H, Chen JH, Xu YF (2020) Patients with mental health disorders in the COVID-19 epidemic. Lancet Psychiatry 7(4):e21. https://doi.org/10.1016/S2215-0366(20)30090-0

5. Rubin GJ, Wessely S (2020) The psychological effects of quarantining a city. BMJ. https://doi.org/10.1136/bmj.m313

6. Center for Disease Control and Prevention (2020) Pandemics can be stressful. https://www.cdc.gov/coronavirus/2019-ncov/dailylife-coping/managing-stressanxiety.html?CDC_AA_refVal= https $\% 3 \mathrm{~A} \% 2 \mathrm{~F} \% 2 \mathrm{Fwww}$.cdc.gov\%2Fcoronavirus $\% 2 \mathrm{~F} 2019-\mathrm{ncov} \%$ 2Fprepare\%2Fmanaging-stress-anxiety.html

7. Lydecker JA, Grilo CM (2019) Food insecurity and bulimia nervosa in the United States. Int J Eat Disord 52(6):735-739. https:// doi.org/10.1002/eat.23074

8. Touyz S, Lacey H, Hay P (2020) Eating disorders in the time of COVID-19. J Eat Disord. https://doi.org/10.1186/ s40337-020-00295-3

9. Ágh T, Kovács G, Pawaskar M, Supina D, Inotai A, Vokó Z (2015) Epidemiology, health-related quality of life and economic burden of binge eating disorder: a systematic literature review. Eat Weight Disord Stud Anorexia Bulimia Obesity 20(1):1-12. https://doi. org/10.1007/s40519-014-0173-9

10. Duarte C, Pinto-Gouveia J, Ferreira C (2015) Expanding binge eating assessment: Validity and screening value of the Binge Eating Scale in women from the general population. Eat Behav 18:41-47. https://doi.org/10.1016/j.eatbeh.2015.03.007

11. Stewart A (2019) One last time. Psychiatry News. https://doi.org/ 10.1176/appi.pn.2019.5b13 
12. Darby A, Hay P, Mond J, Quirk F, Buttner P, Kennedy L (2009) The rising prevalence of comorbid obesity and eating disorder behaviors from 1995 to 2005. Int J Eat Disord 42(2):104-108. https://doi.org/10.1002/eat.20601

13. Erskine HE, Whiteford HA (2018) Epidemiology of binge eating disorder. Curr Opin Psychiatry 31(6):462-470. https://doi.org/10. 1097/YCO.0000000000000449

14. Jenkins PE, Hoste RR, Meyer C, Blissett JM (2011) Eating disorders and quality of life: a review of the literature. Clin Psychol Rev 31(1):113-121. https://doi.org/10.1016/j.cpr.2010.08.003

15. Kessler RC, Berglund PA, Chiu WT, Deitz AC, Hudson JI, Shahly V, Aguilar-Gaxiola S, Alonso J, Angermeyer MC, Benjet C (2013) The prevalence and correlates of binge eating disorder in the World Health Organization world mental health surveys. Biol Psychiat 73(9):904-914. https://doi.org/10.1016/j.biopsych. 2012.11.020

16. Lowe MR, van Steenburgh J, Ochner C, Coletta M (2009) Neural correlates of individual differences related to appetite. Physiol Behav 97(5):561-571. https://doi.org/10.1016/j.physbeh.2009.04. 001

17. Mitchison D, Touyz S, González-Chica DA, Stocks N, Hay P (2017) How abnormal is binge eating? 18-Year time trends in population prevalence and burden. Acta Psychiatr Scand 136(2):147155. https://doi.org/10.1111/acps.12735

18. Mond J, Hay P, Rodgers B, Owen C, Crosby R, Mitchell J (2006) Use of extreme weight control behaviors with and without binge eating in a community sample: Implications for the classification of bulimic-type eating disorders. Int J Eat Disord 39(4):294-302. https://doi.org/10.1002/eat.20265

19. Bulik CM, Trace SE, Mazzeo SE (2013) Chapter 87 eating disorders. In: Goldman MB, Troisi R, Rexrode KM (Eds.). Women and Health, 2:1293-1303. https://doi.org/10.1016/B978-0-12-3849786.00087-X

20. American Psychiatric Association APA (2013) Diagnostic and statistical manual of mental disorders: DSM-5. American Psychiatric Publishing, Arlington

21. Davis C (2013) From passive overeating to "Food addiction": A spectrum of compulsion and severity. ISRN Obesity 2013:1-20. https://doi.org/10.1155/2013/435027

22. Darby A, Hay P, Mond J, Rodgers B, Owen C (2007) Disordered eating behaviours and cognitions in young women with obesity: relationship with psychological status. Int J Obesity 31(5):876882. https://doi.org/10.1038/sj.ijo.0803501

23. Burrows A, Cooper M (2002) Possible risk factors in the development of eating disorders in overweight pre-adolescent girls. Int $\mathbf{J}$ Obes 26(9):1268-1273. https://doi.org/10.1038/sj.ijo.0802033

24. Neumark-Sztainer D, Wall MM, Story M, Perry CL (2003) Correlates of unhealthy weight-control behaviors among adolescents: implications for prevention programs. Health Psychol 22(1):8898. https://doi.org/10.1037//0278-6133.22.1.88

25. Gowers SG, Shore A (2001) Development of weight and shape concerns in the aetiology of eating disorders. British J Psychiatry 179:236-242. https://doi.org/10.1192/bjp.179.3.236

26. Treasure J, Claudino AM, Zucker N (2010) Eating disorders. Lancet (London, England) 375(9714):583-593. https://doi.org/ 10.1016/S0140-6736(09)61748-7

27. Lafrance Robinson A, Kosmerly S, Mansfield-Green S, Lafrance G (2014) Disordered eating behaviours in an undergraduate sample: Associations among gender, body mass index, and difficulties in emotion regulation. Canadian J Behaviour Sci Revue Canadienne Des Sciences Du Comportement 46(3):320-326. https://doi.org/10.1037/a0031123

28. Slevec JH, Tiggemann M (2011) Predictors of body dissatisfaction and disordered eating in middle-aged women. Clin Psychol Rev 31(4):515-524. https://doi.org/10.1016/j.cpr.2010.12.002

29. Reba-Harrelson L, Von Holle A, Hamer RM, Swann R, Reyes ML, Bulik CM (2009) Patterns and prevalence of disordered eating and weight control behaviors in women ages 25-45. Eat Weight Disord Studies Anorexia Bulimia Obesity 14(4):190-198. https:// doi.org/10.1007/bf03325116

30. Doyle AC, le Grange D, Goldschmidt A, Wilfley DE (2007) Psychosocial and physical impairment in overweight adolescents at high risk for eating disorders. Obesity 15(1):145-154. https://doi. org/10.1038/oby.2007.515

31. Tanofsky-Kraff M, Yanovski SZ, Wilfley DE, Marmarosh C, Morgan CM, Yanovski JA (2004) Eating-disordered behaviors, body fat, and psychopathology in overweight and normal-weight children. J Consult Clin Psychol 72(1):53-61. https://doi.org/10. 1037/0022-006X.72.1.53

32. Vander Wal JS, Thelen MH (2000) Eating and body image concerns among obese and average-weight children. Addict Behav 25(5):775-778. https://doi.org/10.1016/S0306-4603(00)00061-7

33. World Health Organization (2011) World health statistics. http:// www.who.int/whosis/whostat/EN_WHS2011_Full.pdf

34. Fairburn CG, Beglin SJ (1994) Assessment of eating disorders: Interview or self-report questionnaire? Int J Eat Disord 16(4):363370. https://doi.org/10.1002/1098-108X(199412)16:4\%3c363:: AID-EAT2260160405\%3e3.0.CO;2-\%23

35. Machado PP, Martins C, Vaz AR, Conceição E, Bastos AP, Gonçalves S (2014) Eating disorder examination questionnaire: psychometric properties and norms for the Portuguese population. Eur Eat Disord Rev 22(6):448-453. https://doi.org/10.1002/erv. 2318

36. Gormally J, Black S, Daston S, Rardin D (1982) The assessment of binge eating severity among obese persons. Addict Behav 7(1):47-55. https://doi.org/10.1016/0306-4603(82)90024-7

37. Brooks SK, Webster RK, Smith LE, Woodland L, Wessely S, Greenberg N, Rubin GJ (2020) The psychological impact of quarantine and how to reduce it: rapid review of the evidence. Lancet 395(10227):912-920. https://doi.org/10.1016/S0140-6736(20) 30460-8

38. Menzel JE, Schaefer LM, Burke NL, Mayhew LL, Brannick MT, Thompson JK (2010) Appearance-related teasing, body dissatisfaction, and disordered eating: A meta-analysis. Body Image 7(4):261-270. https://doi.org/10.1016/j.bodyim.2010.05.004

39. Pila E, Barlow MA, Wrosch C, Sabiston CM (2016) Comparing the body to superior others: Associations with daily exercise and body evaluation in men and women. Psychol Sport Exerc 27:120-127. https://doi.org/10.1016/j.psychsport.2016.08.001

40. Kline RB (2005) Principles and practice of structural equation modeling (2nd ed.). Guilford Press

Publisher's Note Springer Nature remains neutral with regard to jurisdictional claims in published maps and institutional affiliations. 